\title{
Development and Evaluation of an Automated Manual Resuscitator-Based Emergency Ventilator-Alternative
}

Jesica Urbina ${ }^{1}$, Stormy M. Monks ${ }^{1}$, Luis Ochoa ${ }^{2}$, Robert F. Stump ${ }^{3}$, Ryan B. Wicker ${ }^{2}$, Chris Danek ${ }^{4}$, Victor I. Torres ${ }^{1}$, Scott B. Crawford ${ }^{5}$

1. Training and Educational Center for Healthcare Simulation (TECHS), Texas Tech University Health Sciences Center El Paso, El Paso, USA 2. W.M. Keck Center for 3D Innovation, The University of Texas at El Paso, El Paso, USA 3. Emergency Medicine, Texas Tech University Health Sciences Center El Paso, El Paso, USA 4. Regulatory Affairs, Bessel LLC, San Carlos, USA 5. Emergency Medicine; Training and Educational Center for Healthcare Simulation (TECHS), Texas Tech University Health Sciences Center El Paso, El Paso, USA

Corresponding author: Jesica Urbina, jesica.urbina@ttuhsc.edu

\begin{abstract}
Mass casualty incidents such as those that are being experienced during the novel coronavirus disease (COVID-19) pandemic can overwhelm local healthcare systems, where the number of casualties exceeds local resources and capabilities in a short period of time. The influx of patients with lung function deterioration as a result of COVID-19 has strained traditional ventilator supplies. To bridge the gap during ventilator shortages and to help clinicians triage patients, manual resuscitator devices can be used to deliver respirations to a patient requiring breathing support. Bag-valve mask (BVM) devices are ubiquitous in ambulances and healthcare environments, however require a medical professional to be present and constantly applying compression to provide the patient with respirations.
\end{abstract}

We developed an automated manual resuscitator-based emergency ventilator-alternative (AMREV) that provides automated compressions of a BVM in a repetitive manner and is broadly compatible with commercially-available BVM devices approximately 5 inches $(128 \mathrm{~mm})$ in diameter. The AMREV device relieves the medical professional from providing manual breathing support and allows for hands-free operation of the BVM. The AMREV supports the following treatment parameters: 1) adjustable tidal volume $\left(\mathrm{V}_{T}\right), 2$ ) positive end-expiratory pressure (PEEP) (intrinsic and/or external), 3) 1:1 inspiratory: expiratory ratio, and 4) a controllable respiratory rate between 10-30 breaths per minute.

The relationship between the inherent resistance and compliance of the lung and the delivered breaths was assessed for the AMREV device. Adjustable $\mathrm{V}_{T}$ of 110-700 $\mathrm{ml}$ was achieved within the range of simulated lung states. A linear increase in mean airway pressure $\left(\mathrm{P}_{a w}\right)$, from $10-40 \mathrm{cmH}_{2} \mathrm{O}$ was observed, as the resistance and compliance on the lung model moved from normal to severe simulated disease states. The AMREV functioned continuously for seven days with less than $3.2 \%$ variation in delivered $\mathrm{V}_{T}$ and $\mathrm{P}_{a w}$.

Review began 01/21/2021 Review ended 02/11/2021 Published 03/01/2021

๑) Copyright 2021

Urbina et al. This is an open access article distributed under the terms of the Creative Commons Attribution License CC-BY 4.0., which permits unrestricted use, distribution, and reproduction in any medium, provided the original author and source are credited.
Additionally, the AMREV device was compatible with seven commercially-available BVM setups and delivered consistent $\mathrm{V}_{T}$ and $\mathrm{P}_{a w}$ within $10 \%$ between models.

This automated BVM-based emergency-use resuscitator can provide consistent positive pressure, volumecontrolled ventilation over an extended duration when a traditional ventilator is not available. True ventilator shortages may lead to manual resuscitators devices such as the AMREV being the only option for some healthcare systems during the COVID-19 pandemic.

Categories: Emergency Medicine, Medical Simulation, Pulmonology

Keywords: automated bvm compression device, bag valve mask, emergency ventilator, manual resuscitator, mechanical ventilator

\section{Introduction}

In late December 2019, an outbreak of a novel coronavirus disease (COVID-19) was reported in Wuhan, China, and was subsequently identified as a pandemic [1]. Severe COVID-19 disease can result in death due to the development of an acute respiratory distress syndrome (ARDS)-like illness [2]. Invasive ventilation is indicated for adult patients with ARDS-associated respiratory difficulty [3, 4]; however, the influx of patients with lung function deterioration as a result of COVID-19 has strained traditional ventilator supplies [1, 5-7]. To bridge the gap during ventilator shortages, automated manual resuscitator devices can be used to deliver respirations to a patient requiring breathing support [8].

There are currently many open-source solutions that seek to disseminate manual resuscitator (bag-valve mask; BVM) ventilator designs with the hope of bridging the gap during the COVID-19 pandemic [9-11]. 
However, there are important design considerations when using BVM devices for this type of off-label use to prevent further lung injury from barotrauma [12]. First, the design should ensure that the device does not degrade the BVM performance with regard to pressure, $\mathrm{V}_{T}$, and flow waveforms from repetitive device motion. Durability testing has to be performed not only on the mechanical system but also on the BVM device. Secondly, even with a fixed BVM compression setting, the $\mathrm{V}_{T}$ delivered is dependent on the resistance of the airway and the compliance of the lungs [13]. The only respiratory parameter that can be controlled by most devices is the respiratory rate, and while the United States (U.S.) Food and Drug Administration (FDA) has issued emergency use authorizations for devices in which $\mathrm{V}_{T}$ can be selected [14], designs with a fixed stroke length (compression setting) lead to inconsistent $\mathrm{V}_{T}$ delivered as pulmonary parameters change. Ventilator designs should measure expired volumes or predict $\mathrm{V}_{T}$ across ventilator settings for specific pulmonary resistance and compliance parameters.

For this work, it was hypothesized that a low-cost, emergency-use automated BVM-based device could consistently deliver mechanical respirations with a variety of widely commercially-available BVMs. The specific aims were to 1) rapidly design and develop a volume-controlled automated manual resuscitatorbased emergency ventilator-alternative with user-adjustable volume and respiratory rate, 2) evaluate the parameters of $\mathrm{V}_{T}$, rate, and mean airway pressure over different resistance and compliance settings that would be representative of patients with varying lungs states, and 3) establish longevity and implementation of the device across multiple BVM models.

The designed device is a low-cost emergency ventilator-alternative with adjustable stroke length and a housing enclosure that was developed to constrain BVM deformation in a reliable manner to ensure consistent $\mathrm{V}_{T}$ is delivered for each pulmonary parameter. The device, an automated manual resuscitatorbased emergency ventilator-alternative (AMREV), was assessed for $\mathrm{V}_{T}$ delivered, mean airway pressure $\left(\mathrm{P}_{a w}\right)$, and respiratory rate for different simulated models of lung disease. To ensure that variation among commercially-available BVMs did not create the risk of going over threshold $\mathrm{V}_{T}$ or $\mathrm{P}_{a w}$, design considerations were made to ensure that the ventilator device would be widely compatible with BVM models measuring up to approximately $128 \mathrm{~mm}$ (5 inches) in diameter, with a $1.5 \mathrm{~L}$ air reservoir.

\section{Materials And Methods}

\section{A. Design and development of a volume-controlled manual resuscitator-based emergency ventilator}

The AMREV was created using additive manufacturing (hereafter referred to as 3D-printing) technology combined with traditional build techniques that allowed for rapid design iterations and assessments. The design uses an eccentric attachment of a rod and piston assembly to a cam plate driven by a simple lowvoltage geared motor to compress the BVM (Figure. 1). The rod attachment point on the cam controls the amount of compression of the manual resuscitator bag and therefore $\mathrm{V}_{T}$. Respiratory rate of the $30 \mathrm{rpm}$ (without a load) geared motor is controlled by a hardware-based pulse-width modulation (PWM) controller. Full user assembly and operation instructions are included in the supplemental materials Appendix A 'Instructions for Use'.

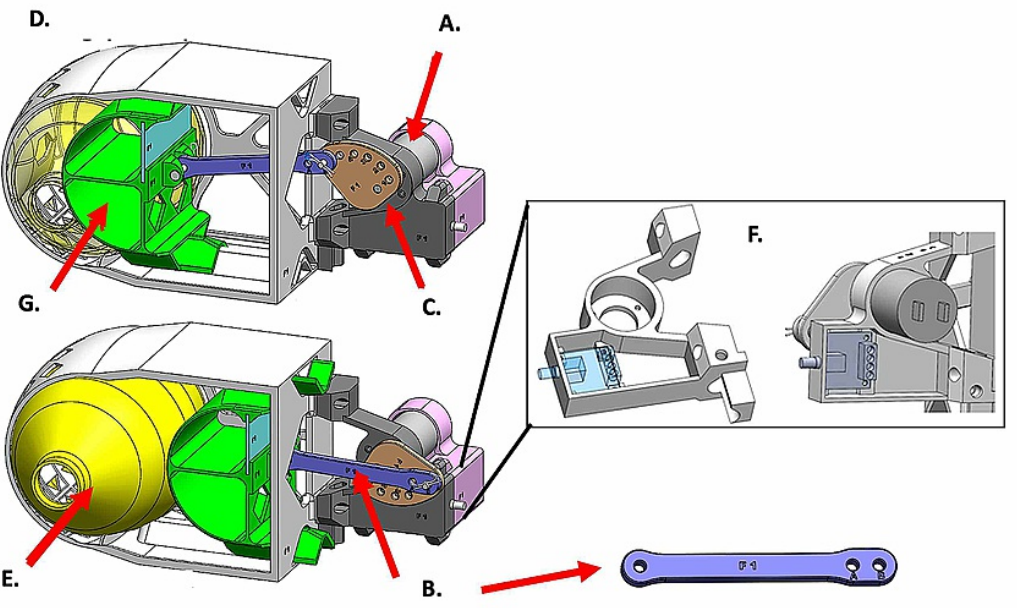

FIGURE 1: Schematic of AMREV, automated manual-resuscitator based emergency ventilator-alternative 
The 3D-printed components of the device were made of polycarbonate material fabricated on Stratasys 400 $\mathrm{mc}, 450 \mathrm{mc}$, and $900 \mathrm{mc}$ Fortus series printers (Rehovot, Israel). Polycarbonate was selected due to its strength, availability, durability, and acceptability in medical applications. Electrical power to the AMREV unit was provided by a commercially-available low-voltage 12V 2A DC power supply. Electrical connections were made within the enclosed 3D printed motor mount, and secured using screw terminals, solder, and commercial spade clips. Hitch pin clips were used to secure the clevis pins of the mechanical piston rod, a set screw is used to attach the adjustable-length cam to the motor shaft, and screws hold the electronics cover to the motor mount.

A rapid, iterative design/simulate, build, and test approach was used to converge on the final design. The main design considerations included 1) compatibility with commercial BVMs, 2) a piston-cylinder and sliding mechanism approach for bag compression, 3) device conforming to BVM shape to reduce stress, 4) minimizing weight, 5) minimizing ventilation dead space volume by allowing mounting near the patient's mouth using a bedside IV pole, 6) an electric motor needed to drive the mechanism, and 7) compatibility with additive manufacturing (AM); specifically, fused deposition modeling (FDM) with polycarbonate material. Dimensions were selected during the design phase to ensure ease of assembly, operation on a sliding contact mechanism, and the specified range of piston travel. All were achieved by accounting for tolerances of the FDM process. To reduce variability in the manufacturing process and in device performance, the design excluded the use of support structures on the critical piston linear slide or BVM contact surfaces. Solid modeling was performed in Solidworks (Version 2019-20). Prototyping by 3D printing allowed rapid production and advancement through six major design iterations. A future publication will discuss the use of simulation by finite element analysis (FEA) in parallel with the AMREV design iterations as a precursor to device-life testing.

\section{B. Tidal volume and pressure assessment}

Prototypes were assessed for general function, piston movement, and length of piston travel needed to compress the manual resuscitator to deliver an approximate tidal volume between $200-700 \mathrm{ml}$ in a patient with normal lung function with resistance $5 \mathrm{cmH}_{2} \mathrm{O} \cdot \mathrm{L}^{-1} \cdot \mathrm{s}^{-1}$ and compliance $50 \mathrm{ml} \cdot \mathrm{cmH}_{2} \mathrm{O}^{-1}$. Device assessments were performed with a RespiTrainer Advance ${ }^{\mathrm{TM}}$ and QuickLung ${ }^{\circledR}$ (IngMar Medical Ltd., Pittsburg, PA, USA). After functional confirmation, specific parameter testing and device calibration was performed using an ASL 5000 ${ }^{\text {тм }}$ Breathing Simulator. (IngMar Medical Ltd., Pittsburg, PA, USA). The same IngMar ${ }^{\circledR}$ ASL 5000 was used for all testing parameters. Following data collection, the ASL 5000 was connected to a hospital-certified ventilator to compare calibration of $\mathrm{V}_{T}$ and pressures. The device was found to correlate within $5 \%$ across assessed parameters.

To measure the effect of patient lung resistance and compliance on $\mathrm{V}_{T}$ delivered, variation was assessed across different pulmonary parameter models. The initial disease states for testing were chosen based on discussions with a pulmonologist $\backslash$ critical care physician at our local county hospital about expected pulmonary parameters based on early COVID-19 patient information available. The simulated lung models used during testing had predefined resistance (R) (cmH2O.L-1.s-1) and compliance (C) (ml.cmH2O-1) parameters and were labeled 'normal' (R5C50), 'mild disease' (R6C20) and, 'moderate disease' (R10C10) (see page 2 of the IngMar product sheet here (https://pdf.medicalexpo.com/pdf/ingmar-medical/quicklungprecision-test-lung/68861-105019.html). Additionally, a 'severe disease' state (R50C10) was tested for 24 hours to meet FDA and international standard requirements for basic safety and essential performance of ventilatory support (ISO 80601-2-80:2018; 201.104) [15, 16]. All four simulated pulmonary parameters were defined in the RespiSim ${ }^{\circledR}$ software (Version 3.6) to have zero muscle effort to simulate a paralyzed patient.

A single assembled unit with a $30 \mathrm{rpm}$ motor, run at $100 \%$ power was paired with an adult Rüsch ${ }^{\circledR}$ (Wayne, PA, USA) BVM to assess device capability to meet ventilation requirements of patients with ARDS. An AirLife $^{\mathrm{TM}}$ viral filter (Vyaire Medical, IL, USA) was attached to the BVM and connected to the ASL 5000 using the supplied five feet coil wrapped air hose. Sequential testing was performed across all connection parameters; rod positions A and B, with cam positions one to six (position A-six is not allowed due to the travel distance of the piston in the housing).

A minimum set of data for ten breaths were recorded within the RespiSim ${ }^{\circledR}$ software for analysis. Each stroke length and power level test was repeated using each of the three simulated patient parameters (normal, mild, and moderate lung disease). The RespiSim ${ }^{\circledR}$ software paired with the ASL 5000 breathing simulator recorded the variables of respiratory rate, Paw $\left(\mathrm{cmH}_{2} \mathrm{O}\right)$, inspiratory to expiratory (I:E) ratio, and $\mathrm{V}_{T}(\mathrm{ml})$ for each test.

\section{Longevity and implementation}

Ventilatory parameters for seven BVMs representing six commonly-used, commercially-available models 


\section{Cureus}

and manufacturers were assessed in conjunction with the AMREV (Figure 2, Table 1). Materials varied by brand and model and were one of three materials: silicone, polyvinyl chloride (PVC), or styrene-ethylenebutylene-styrene (SEBS) polymer [17-22]. For comparison testing, each bag was paired with a single AMREV device housing enclosing a $30 \mathrm{rpm}$ motor, run at $75 \%$ power, with rod-cam position combination A-4 (stroke length $6.4 \mathrm{~cm})$. Parameters of $\mathrm{V}_{T}(\mathrm{ml})$ and pressure $\left(\mathrm{cmH}_{2} \mathrm{O}\right)$ for each breath were recorded by the ASL 5000 RespiSim software and exported for review. During longevity testing, each BVM was connected to an Ingmar Quicklung ${ }^{\mathrm{TM}}$ with settings of compliance $50 \mathrm{ml} . \mathrm{cmH}_{2} \mathrm{O}^{-1}$ and resistance $5 \mathrm{cmH}_{2} \mathrm{O}^{-\mathrm{L}^{-1}}$. ${ }^{-1}$. Each BVM was temporarily disconnected from the Quicklung ${ }^{\mathrm{TM}}$ device for data collection with the ASL 5000 breathing simulator.

Means and standard deviations were calculated for $\mathrm{P}_{a w}$ and $\mathrm{V}_{T}$ across 13 breaths. The $\mathrm{V}_{T}$ and $\mathrm{P}_{a w}$ delivered at a single connection setting were compared between seven BVM setups for each of four disease states. Longitudinal comparisons of $\mathrm{P}_{a w}$ and $\mathrm{V}_{T}$ were also collected and analyzed at day zero and day seven for five BVM setups. Additionally, a single Rüsch BVM was also tested at 30 and 45 days to evaluate the consistency of $\mathrm{P}_{a w}$ and $\mathrm{V}_{T}$ delivered after approximately 1.3 million compressions. Data was not recorded on one Carefusion BVM setup due to a component failure on the AMREV on the seventh day of continuous operation.

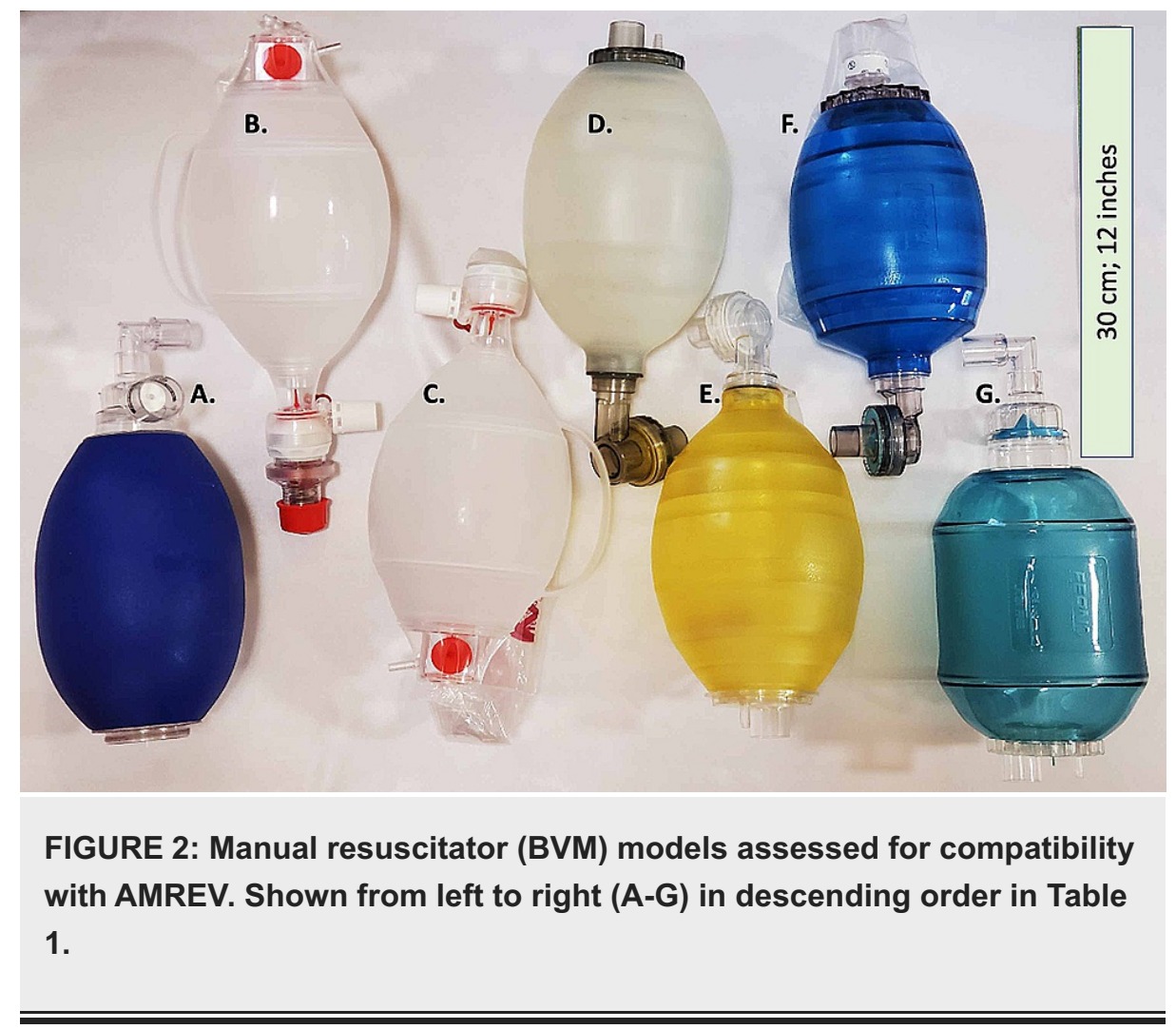




\section{Cureus}

\begin{tabular}{|llllll|}
\hline & Brand & Model & Material & Bag diameter (mm; in) \\
\hline A & Carefusion & AirLife $^{\circledR}$ & PVC & $128.5[5.06]$ \\
B & Ambu & AMBU $^{\circledR}$ Bag SPUR $^{\circledR}$ II & SEBS & $124[4.88]$ \\
C & Ambu & AMBU $^{\circledR}$ Bag SPUR $^{\circledR}$ II w/ PEEP valve & SEBS & $124[4.88]$ \\
D & Laerdal & Laerdal LSR Reusable Resuscitator & Silicone & $127[5.0]$ \\
E & Laerdal & Laerdal The Bag II & PVC & $128[5.08]$ \\
F & Rüsch & Resuscitator BVM & PVC & $122[4.80]$ \\
G & Ferno & Adult manual resuscitator & PVC & $126[4.96]$ \\
\hline
\end{tabular}

TABLE 1: Brand and model of the BVM devices tested with listed material from manufacturer product information [17-22].

PEEP - positive end-expiratory pressure

Results

\section{A. Development of an automated volume-controlled BVM-based emergency ventilator-alternative}

The AMREV was designed as a rapidly-deployable, hands-free automated manual resuscitator-based compression device that delivers respirations when there is no other ventilator alternative (Figure 1).

Consistent $\mathrm{V}_{T}$ was delivered with six commercially-available BVMs trialed with the AMREV at each user selectable setting (Figure 2). The attachment points on the cam (Figure $1 \mathrm{C}$ ) are labeled number one to six, with varying distances from the center and determine the travel distance of the piston rod and therefore, the $\mathrm{V}_{T}$ delivered with each breath. Each hole on the cam combined with the piston rod attachment point (A or B; Figure $1 B$ ) corresponds to a volume increment of approximately $50-110 \mathrm{ml}$ depending on patient lung parameters. The piston rod is attached to a curved piston inside of the device housing enclosure (Figure $1 D$ $\mathrm{G})$ that travels along a triangular-shaped linear slide to maintain smooth and directed operation toward a fixed wall. The BVM (Figure $1 E$ ) is placed between the piston and the wall, and with each cycle, the motor compresses the device to deliver a breath. The wall of the housing is curved to match the shape of the BVM. Return of the piston to its non-compressed state allows the bag to recoil and draw in oxygen-supplemented air. The BVM allows the patient to exhale through a one-way expiratory valve. After recoil, the BVM in the device is prepared to deliver another breath. There are 11 possible combinations between the attachment points $A$ and $B$ on the piston rod and the cam (A one to five; B one to six) (Figure $1 B-C$ ). Different combinations correspond to differing degrees of bag compression by the piston. The design uses a lowvoltage, high-torque geared motor (Figure $1 \mathrm{~A}$ ) with an adjustable cycle of up to $30 \mathrm{rpm}$ to drive an adjustable-length piston rod (Figure $1 B$ ) that is attached to a cam (Figur 1C) on the motor shaft. The user can adjust the motor rotation rate (breathing rate) by turning a knob on the outside of the motor casing (Figure $1 F$ ). Parts and implemented design are shown in Figure 3.
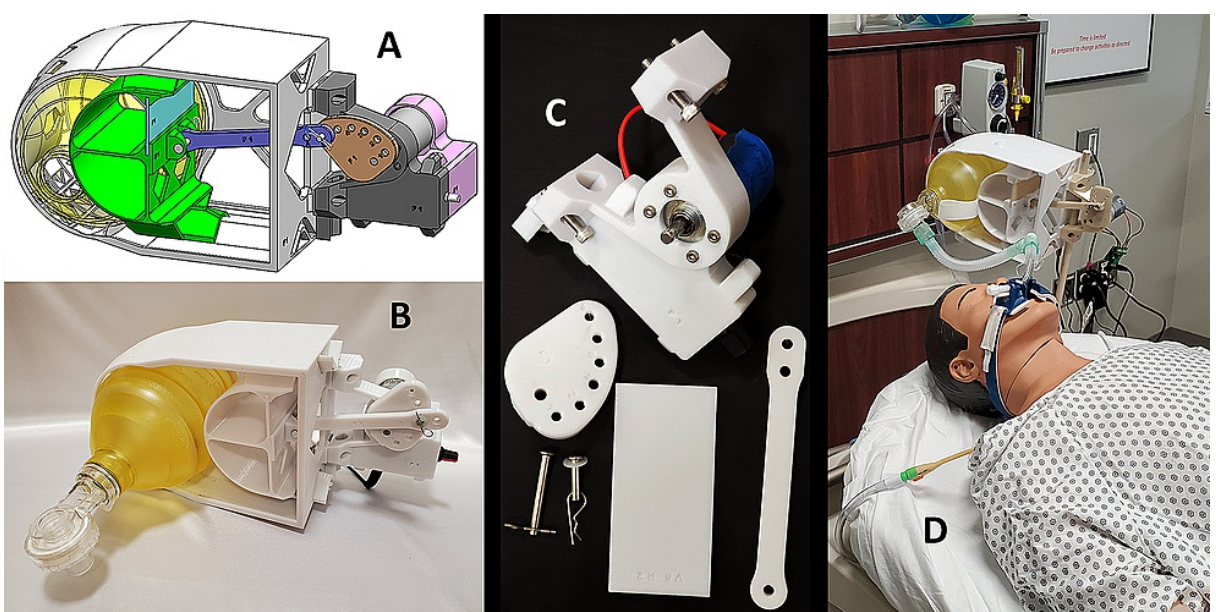
FIGURE 3: Design and function of the 3D-printed AMREV. A) Schematic for the device, B-C) 3D-printed parts, and D) fully assembled prototype device shown on a Laerdal MegaCode Kelly ${ }^{\mathrm{TM}}$ simulation manikin.

\section{B. Tidal volume and pressure assessment for representative patient models with varying degree of lung function}

Each specific setting of the rod and cam position selected by the user, corresponds to the degree of compression for the BVM, however, the actual $\mathrm{V}_{T}$ delivered depends on patient lung resistance and compliance. To measure the effect of different pulmonary disease states on delivered volume, $\mathrm{V}_{T}$ was assessed across assigned lung parameters. Respiratory rate was controlled by a $30 \mathrm{rpm}$ motor operated at full power. The average breaths delivered per minute (bpm) for all 11 configurations was $27.6 \pm 1.2 \mathrm{bpm}$. No variations in respiratory rate were observed across these lung states.

In a simulated patient with normal lung function (R5C50), $\mathrm{V}_{T}$ increased by $74 \pm 6 \mathrm{ml}$ for each change in cam settings one to five on piston rod position A and $91 \pm 13 \mathrm{ml}$ for cam settings one to six using piston rod position B (Figure 4, Table 2). As resistance of the lungs increased and compliance decreased, a decline in $\mathrm{V}_{T}$ was observed within the same rod and cam settings. In the mild (R6C20) simulated lung disease model, $\mathrm{V}_{T}$ increased in correspondence with changes in cam settings. Changes were $58 \pm 10 \mathrm{ml}$ and $85 \pm 13 \mathrm{ml}$ for rod positions A and B, respectively. A similar trend was observed in the moderate (R10C10) disease model where changes of $54 \pm 5 \mathrm{ml}$ and $75 \pm 10$ were noted for rod positions $\mathrm{A}$ and $\mathrm{B}$, respectively. A linear regression trend with $\mathrm{R}^{2}=1 \pm 0.005$ in $\mathrm{V}_{T}$ was observed across all simulated lung types, and the slope describes the approximate volume change per cam setting (Figure 4).

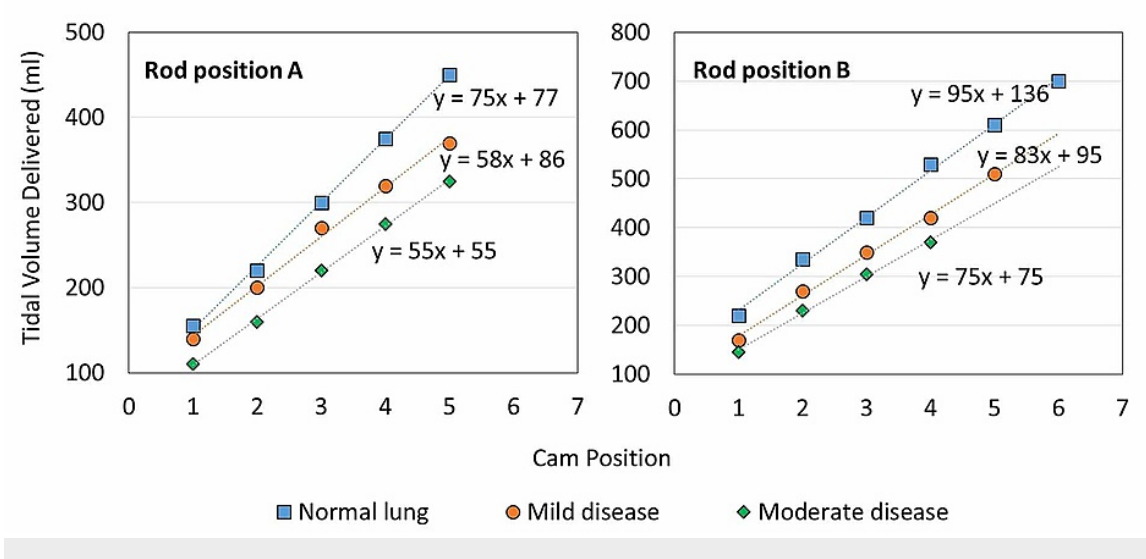

FIGURE 4: Tidal volume delivered for simulated patient types for rod settings $A$ and $B$ and cam settings 1-6. 


\section{Cureus}

\begin{tabular}{|c|c|c|c|c|c|c|c|c|}
\hline \multirow[b]{2}{*}{$\begin{array}{l}\text { Rod } \\
\text { Setting }\end{array}$} & \multirow[b]{2}{*}{$\begin{array}{l}\text { Cam } \\
\text { Setting }\end{array}$} & \multicolumn{3}{|c|}{ 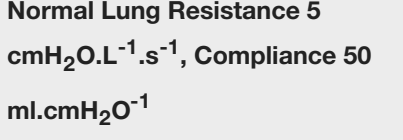 } & \multicolumn{2}{|c|}{$\begin{array}{l}\text { Mild Disease Resistance } 6 \\
\mathrm{cmH}_{2} \mathrm{O} \cdot \mathrm{L}^{-1} \cdot \mathrm{s}^{-1} \text {, Compliance } 20 \\
\mathrm{ml}^{\mathrm{cmHH}} \mathrm{O}^{-1}\end{array}$} & \multicolumn{2}{|c|}{$\begin{array}{l}\text { Moderate Disease Resistance } 10 \\
\mathrm{cmH}_{2} \mathrm{O} . \mathrm{L}^{-1} \cdot \mathrm{s}^{-1} \text {, Compliance } 10 \\
\mathrm{ml} . \mathrm{cmH}_{2} \mathrm{O}^{-1}\end{array}$} \\
\hline & & $\begin{array}{l}\text { Pressure } \\
\left(\mathrm{cmH}_{2} \mathrm{O}\right)\end{array}$ & $\begin{array}{l}\text { Volume } \\
\text { (ml) }\end{array}$ & Pres & ure $\left(\mathrm{cmH}_{2} \mathrm{O}\right)$ & Volume (ml) & $\begin{array}{l}\text { Pressure } \\
\left(\mathrm{cmH}_{2} \mathrm{O}\right)\end{array}$ & Volume (ml) \\
\hline A & 1 & 3.6 & 155 & 7.2 & & 140 & 12.2 & 110 \\
\hline A & 2 & 5.3 & 220 & 10.5 & & 200 & 17 & 160 \\
\hline A & 3 & 7.2 & 300 & 14 & & 270 & 22.5 & 220 \\
\hline A & 4 & 9 & 375 & 17.4 & & 320 & 28 & 275 \\
\hline A & 5 & 10.7 & 450 & 20.5 & & 370 & 34.5 & 325 \\
\hline B & 1 & 5.1 & 220 & 8.7 & & 170 & 14.5 & 145 \\
\hline B & 2 & 7.6 & 335 & 14 & & 270 & 23 & 230 \\
\hline B & 3 & 10 & 420 & 18 & & 350 & 32 & 305 \\
\hline B & 4 & 12.1 & 530 & 22 & & 420 & 38.5 & 370 \\
\hline B & 5 & 14 & 610 & 26 & & 510 & $\mathrm{~N} / \mathrm{A}$ & $\mathrm{N} / \mathrm{A}$ \\
\hline B & 6 & 15.6 & 700 & N/A & & N/A & N/A & $\mathrm{N} / \mathrm{A}$ \\
\hline
\end{tabular}

TABLE 2: Respiratory parameters for all adjustable-length rod and cam configurations in each of three pulmonary resistance and compliance settings.

Similar trends were observed in measured $\mathrm{P}_{a w}$ for all three patient models. A linear increase in $\mathrm{P}_{a w}\left(\mathrm{R}^{2}=1\right)$ as a function of $\mathrm{V}_{T}$ demonstrates that as $\mathrm{V}_{T}$ increases, a corresponding increase in $\mathrm{P}_{a w}$ was observed (Figure 5) [4].

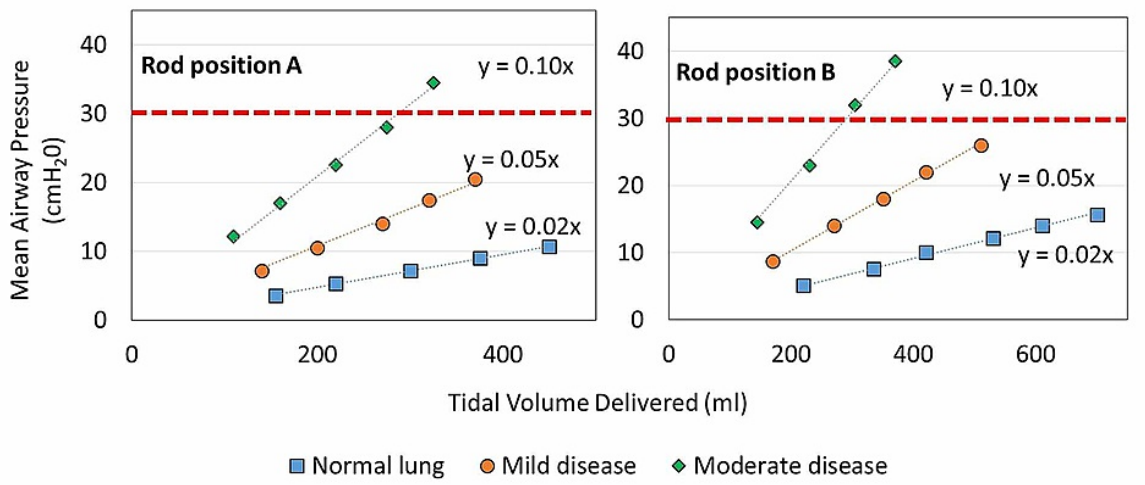

FIGURE 5: Mean airway pressure measured for simulated patient lung types as a function of tidal volume delivered. Red dashed line denotes maximum airway pressure threshold for ARDS treatment recommendations.

The AMREV was operated continuously for 24 hours using the severe (R50C10) disease model and positive end-expiratory pressure (PEEP) $10 \mathrm{cmH}_{2} \mathrm{O}$ to meet ISO 80601-2-80:2018; 201-104 testing requirements [15]. Waveform data before and after this simulated worst-case condition testing was recorded (Figure 6A-B). To meet this requirement, the AMREV was operated with an Ambu Spur II BVM with external PEEP 10, and at 
setting $A 3$ with a respiratory rate of $20 \mathrm{rpm}$. The average measured $\mathrm{P}_{a w}$ for 13 breaths at time zero was $39.9 \pm$ $0.1 \mathrm{cmH}_{2} \mathrm{O}$ and after 24 hours was $39.7 \pm 0.1 \mathrm{cmH}_{2} \mathrm{O}$. The average $\mathrm{V}_{T}$ delivered over 13 breaths at time zero was $370 \pm 1 \mathrm{ml}$ and after 24 hours was $362 \pm 1 \mathrm{ml}$.
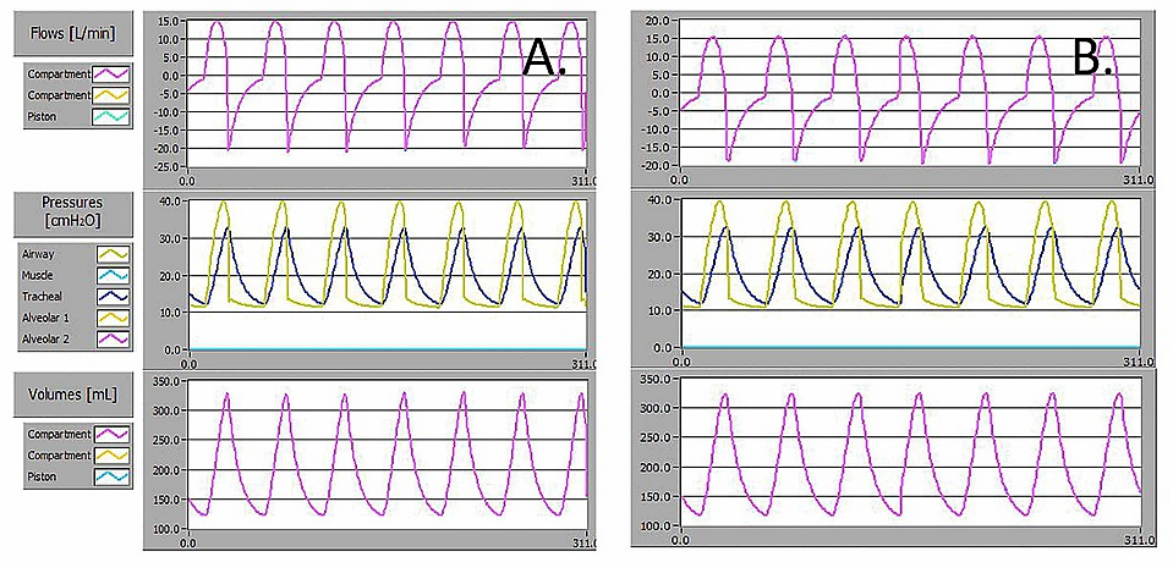

FIGURE 6: Flow, Paw, and VT waveforms for delivered breaths for a severe disease simulated patient lung model with resistance $\mathbf{5 0}$ cmH2O.L-1.s-1 and compliance $10 \mathrm{ml} . \mathrm{cmH} 2 \mathrm{O}-1$ using an AMBU Spur II bag with $10 \mathrm{cmH} 2 \mathrm{O}$ PEEP at A) day zero, and B) after 24 hours of continuous operation.

\section{Longevity and implementation of AMREV across multiple BVM models}

Widespread use of the AMREV relies on availability and compatibility with commercially-available BVMs. We conducted a study to assess the inherent variability of different BVM models. Seven BVM setups representing six different BVM models and manufacturers were assessed (Figure 2). Two Ambu ${ }^{\circledR}$ bags, one with and one without external PEEP, were independently evaluated. $\mathrm{P}_{a w}$ variation between bags was calculated (Figure 2C). The Ambu® ${ }^{\circledR}$ bag with external PEEP was excluded due to baseline $\mathrm{P}_{a w}$ elevation. Variation within each individual bag type in $\mathrm{V}_{T}$ and $\mathrm{P}_{a w}$ was $<0.5 \%$ for each BVMs tested, across four simulated lung models. The $\mathrm{P}_{a w}$ for all six bags were $10.1 \pm 0.9 \mathrm{cmH}_{2} \mathrm{O}$ for the normal lung model, $19.7 \pm 1.7$ $\mathrm{cmH}_{2} \mathrm{O}$ for mild disease, $32.4 \pm 2.2 \mathrm{cmH}_{2} \mathrm{O}$ for moderate disease, and $40.4 \pm 3.0$ for the severe disease model (Figure 7A). The average $\mathrm{V}_{T}$ for all bags was $460 \pm 45 \mathrm{ml}$ for the normal lung model, $404 \pm 37 \mathrm{ml}$ for mild disease, $353 \pm 25 \mathrm{ml}$ for moderate disease, and $351 \pm 36 \mathrm{ml}$ for the severe disease model (Figure $7 B$ ). Overall, variation was less than $10 \%$ for $\mathrm{P}_{a w}$ and $\mathrm{V}_{T}$ across all bags for each of the four simulated lung models. 


\section{Cureus}
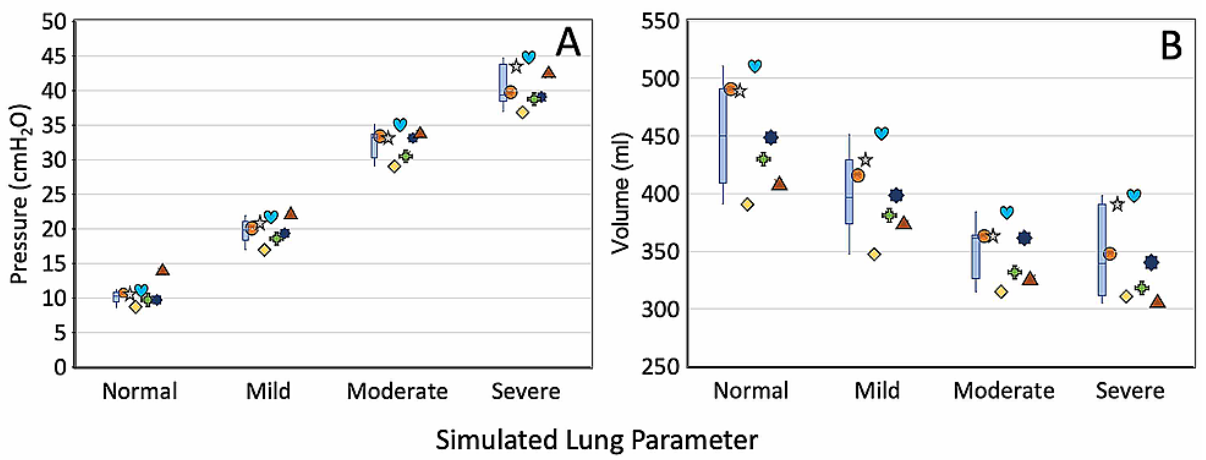

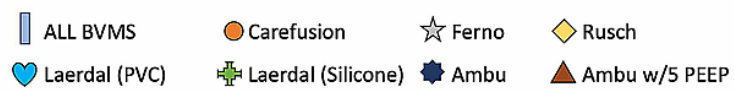

FIGURE 7: A) Tidal volume VT and B) mean airway pressure Paw measurement, from different BVM models in simulated patient testing with (resistance cmH2O.L-1.s-1, compliance ml.cmH2O-1) of 'normal' $(5,50)$, 'mild' $(6,20)$, 'moderate' $(10,10)$ and 'severe' $(50,10)$, respectively.

Long-term, multi-day, testing was performed with six BVM devices with settings of compliance 50 ml. $\mathrm{cmH}_{2} \mathrm{O}^{-1}$ and resistance $5 \mathrm{cmH}_{2} \mathrm{O} \cdot \mathrm{L}^{-1} \cdot \mathrm{s}^{-1}$ to assess for variation within the same BVM (Figure 8 ). One of the AMREV devices that housed the Carefusion BVM had a component failure on the seventh day and did not have data recorded prior to its failure. The respiratory rate at $75 \%$ motor power was $22 \pm 2 \mathrm{bpm}$. $\mathrm{V}_{T}$ and $\mathrm{P}_{a w}$ were independent of the respiratory rate. Data for five BVM/device pairings B-F listed in Table 1 were recorded at seven days. After a one-week course (>230,000 cycles) of continuous use, the $\mathrm{V}_{T}$ variation observed between each bag was less than $1.5 \%$ (Table 3). Similar results were observed with $\mathrm{P}_{a w}$ where differences were all within 1\%, with one exception; the Laerdal LSR Silicone bag showed variability of 3.2\% in $\mathrm{P}_{a w}$ after one week of continued use (Table 4). One device with the Rüsch ${ }^{\circledR}$ BVM (Table 3), completed the seven-day test and continued to 45 days of operation. This BVM showed that $\mathrm{V}_{T}$ and $\mathrm{P}_{a w}$ variation was within $3.8 \%$ even over the extended operation.

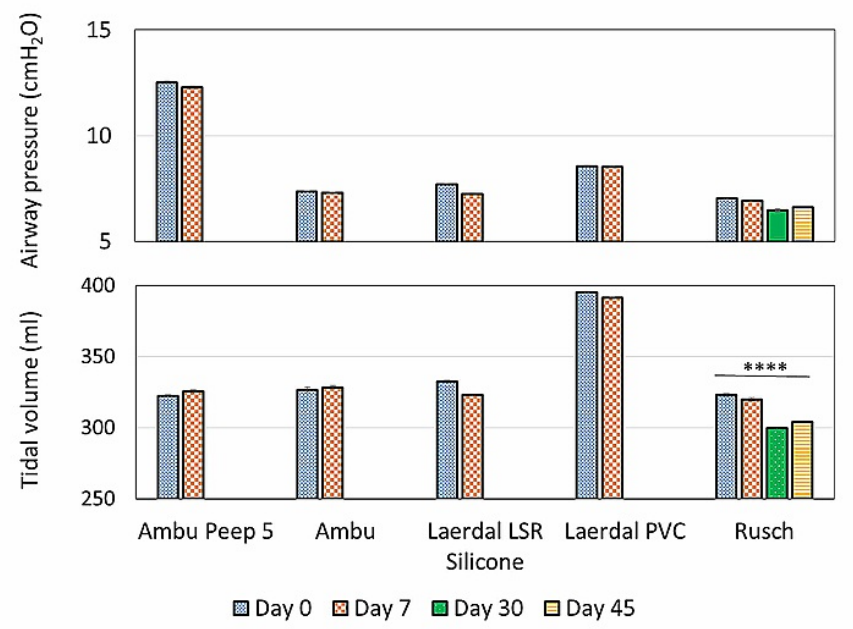

FIGURE 8: VT and Paw for 5 models of manual resuscitator devices in a 'normal' patient model with resistance $=5 \mathrm{cmH} 2 \mathrm{O} . \mathrm{L}-1 . \mathrm{s}-1$ and compliance $=\mathbf{5 0} \mathrm{ml} . \mathrm{cmH} 2 \mathrm{O}-1$ at trial start, after 1 week, 30 days, and 45 days of continuous use. Error bars lie within the column. Ordinary oneway ANOVA $\mathbf{P}=\mathbf{0 . 0 0 0 1}$ for Rüsch BVM. 


\begin{tabular}{|c|c|c|c|c|c|}
\hline & Ambu PEEP 5 (ml) & Ambu (ml) & Laerdal LSR Silicone (ml) & Laerdal PVC (ml) & Rüsch (ml) \\
\hline Day 0 & $322+/-1$ & $327+/-2$ & $332+/-2$ & $395+/-0.5$ & $323+/-1$ \\
\hline Day 7 & $325+/-1$ & $328+/-2$ & $323+/-1$ & $391+/-0.5$ & $320+/-1$ \\
\hline Day 30 & & & & & $300+/-0.4$ \\
\hline Day 45 & & & & & $304+/-0.4$ \\
\hline Percent difference & 0.5 & 0.2 & 1.4 & 0.5 & 3.7 \\
\hline
\end{tabular}

TABLE 3: Average tidal volume delivered ( $\mathrm{ml}$ ) for each BVM tested, at the start of the extended day trial, and after the completion of seven days of continuous use.

\begin{tabular}{|c|c|c|c|c|c|}
\hline & $\begin{array}{l}\text { Ambu PEEP } 5 \\
\left(\mathrm{cmH}_{2} \mathrm{O}\right)\end{array}$ & $\begin{array}{l}\text { Ambu } \\
\left(\mathrm{cmH}_{2} \mathrm{O}\right)\end{array}$ & $\begin{array}{l}\text { Laerdal LSR Silicone } \\
\left(\mathrm{cmH}_{2} \mathrm{O}\right)\end{array}$ & $\begin{array}{l}\text { Laerdal PVC } \\
\left(\mathrm{cmH}_{2} \mathrm{O}\right)\end{array}$ & $\begin{array}{l}\text { Rüsch } \\
\left(\mathrm{cmH}_{2} \mathrm{O}\right)\end{array}$ \\
\hline Day 0 & 12.5 & 7.3 & 7.7 & 8.6 & 7.0 \\
\hline Day 7 & 12.3 & 7.3 & 7.2 & 8.5 & 6.9 \\
\hline Day 30 & & & & & 6.5 \\
\hline Day 45 & & & & & 6.6 \\
\hline $\begin{array}{l}\text { Percent } \\
\text { difference }\end{array}$ & 1.0 & 0.3 & 3.2 & 0.2 & 3.8 \\
\hline $\begin{array}{l}\text { TABLE 4: } \\
\text { and after }\end{array}$ & $\begin{array}{l}\text { ige measure } \\
\text { days of co }\end{array}$ & $\begin{array}{l}\text { k airway } \\
\text { us use. }\end{array}$ & ssures $(\mathrm{cmH2O})$ a & tart of the & led day \\
\hline
\end{tabular}

\section{Discussion}

This study suggests that the use of a BVM-based ventilator system can deliver appropriate respiratory support in the event of a ventilator shortage. The AMREV can be used to support patients with respiratory distress including respiratory failure based on the range of $\mathrm{V}_{T}$, pressures, and respiratory rates supported. Simulation testing was performed using realistic patient models and transition to real patient care is anticipated based on the study results.

The differences observed in $\mathrm{P}_{a w}$ as a function of $\mathrm{V}_{T}$ delivered were consistent with defined characteristics of pulmonary resistance and compliance (Figure 5). Treatment recommendations for patients with ARDS suggest $\mathrm{P}_{a w}$ should not exceed $30 \mathrm{cmH}_{2} \mathrm{O}$. For this device, rod and cam position pairings that produce lower $\mathrm{V}_{T}$ should be used in more severe pulmonary disease to deliver ventilations below this threshold. The device was able to provide safe ventilatory support while not exceeding this $\mathrm{P}_{a w}$ threshold. As external PEEP, provided by existing BVM peripherals, is increased it is important to use lower $\mathrm{V}_{T}$ settings to ensure safe ventilation of lungs with low compliance.

The AMREV demonstrated compatibility with different models of BVM that had diameters ranging from 122$128.5 \mathrm{~mm}$ or approximately five inches. These bags are representative of adult BVMs that have an air reservoir of $\sim 1.5 \mathrm{~L}$. While differences between BVMs were identified, overall variation was less than $10 \%$ for $\mathrm{P}_{a w}$ and $\mathrm{V}_{T}$ delivered across all bags as assessed over four simulated lung states.

Device life testing demonstrated consistent and predictable delivery of ventilation over an array of patient pulmonary parameters and over time using multiple BVMs. Specifically, six devices were tested over seven days and no failures were identified with the BVM devices or housing structure. Two devices failed at seven days. One of these devices allowed for data collection on the seventh day, however, data was not obtainable from the other device to include in longevity analysis (Tables 3-4). One device continued to function for 45 days with no failures of the BVM, housing, or motor. The failures identified on all devices were related to 
motor fatigue, with the average device life being 17 days. Motor fatigue was predictable due to increased noise at least 24 hours prior to failure. Future design iterations will incorporate higher-quality motors to improve longevity.

Even with variations in respiratory rate from the PWM setting, respiratory parameters of $\mathrm{V}_{T}$ and $\mathrm{P}_{a w}$ were consistent for each rod and cam setting. Although the device was periodically stopped for testing, this practice is consistent with clinical use. In a clinical setting, a patient may be moved or disconnected from a ventilator to perform testing, thus the study demonstrated that even with minor variations in respiration rate from motor power adjustments during these periods of disconnection and testing, the other respiratory parameters remained consistent.

As described in previous literature, manual BVM compressions, i.e. bagging, is variable in rate and $\mathrm{V}_{T}$ delivered [9]. The study findings suggest that the AMREV is able to provide a consistent rate and $\mathrm{V}_{T}$ of respirations and is thus expected to be more reliable and safer than manual bagging. Additionally of interest to medical professionals, the AMREV is adaptable to multiple clinical environments with a housing design and attachment configuration that supports mounting of the device to a bedside IV pole. This design consideration minimizes the distance from the BVM to the endotracheal tube and limits the risk of rebreathing $\mathrm{CO}_{2}$.

The study findings suggest that this BVM-based emergency use ventilator can provide consistent positive pressure volume-controlled ventilation over an extended duration until a traditional ventilator becomes available. This device is only intended for use when a traditional ventilator is not available. True shortages may lead to the presented solution being a viable option for some regions during a large-scale health emergency. An imminent predicted need for ventilators resulted in the issuance of an emergency use authorization by the U.S. FDA to increase the availability of devices that provide ventilatory support and even described a new class of ventilation device termed 'emergency use resuscitator systems' (EURS) [23]. While these guidelines were established specifically for the COVID-19 pandemic, the knowledge and design innovation obtained from this rapid period of discovery may have lasting effects on future ventilator devices.

\section{Conclusions}

In response to the COVID-19 pandemic that has overwhelmed healthcare systems worldwide, the authors designed, rapidly prototyped, and tested a 3D-printed automated volume-controlled manual-resuscitator based ventilator-alternative. The AMREV was developed to provide respirations with commercially-available BVMs when a ventilator is not available. User-adjustable configurations allow for quick adjustment of tidal volume and respiratory rate and are within the treatment recommendations from the ARDS Network. As the COVID-19 crisis is overwhelming health care systems, leaving some institutions without an adequate supply of ventilators, the AMREV provides a potentially life-saving alternative.

\section{Appendices}




\section{Cureus}

Appendix A - Instructions for Use

Caution: Rx only

Minnetronix Medical

1635 Energy Park Drive

St Paul, MN 55108

651-917-4060 www.minnetronix.com

Automated Manual Resuscitator-Based Emergency Ventilator-Alternative Texas Power Bag Breather

(Texas Breather ${ }^{\mathrm{TM}}$ )

\section{DRAFT INSTRUCTIONS FOR USE}

This hands-free Bag-Valve-Mask (BVM) compression device has not been FDA cleared or approved. This hands-free BVM compression device has been authorized by FDA under an EUA.

This hands-free BVM compression device is authorized only for the duration of the declaration that circumstances exist justifying the authorization of the emergency use of ventilators, ventilator tubing connectors, and ventilator accessories under section $564(\mathrm{~b})(1)$ of the Act, 21 U.S.C. $\S 360 \mathrm{bbb}-3(\mathrm{~b})(1)$, unless the authorization is terminated or revoked sooner.

Figure 1. Texas Power Bag Breather (Texas Breather ${ }^{\text {TM }}$ )

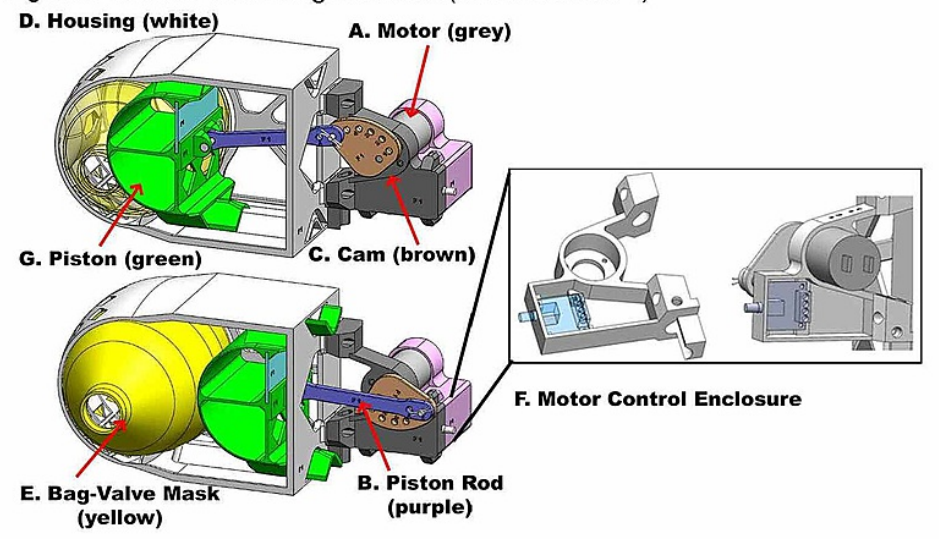

LBL-1002 rev02

FIGURE 9: Appendix A.1 Instructions for use 


\section{Cureus}

Figure 2. Adjustable length Cam (brown) and Piston Rod (purple)

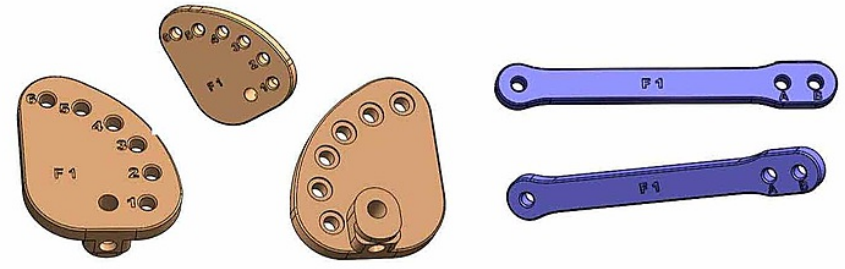

Indications for Use

The Texas Breather ${ }^{T h}$ is intended for emergency use during the COVID-19 pandemic under Emergency Use Authorization for short-term total mechanical ventilation support, when a mechanical ventilator is not available. The Texas Breather ${ }^{\mathrm{rt}}$ is intended to be used for a single patient at a time, together with commercially available, FDA-cleared, self-inflating manual resuscitators (bag-valve mask assemblies) with PEEP valves, pressure relief valves, and viral filtration accessories.

\section{Cautions and Warnings}

- The Texas Breather ${ }^{\mathrm{TM}}$ is not approved or cleared by the US FDA. It has Emergency Use Authorization from the US FDA for use during the COVID-19 pandemic only.

- The Texas Breather ${ }^{\mathrm{TM}}$ has not been cleared or approved by US FDA. Its safety and effectiveness for use under ventilator shortages from COVID-19 have not been established.

- The Texas Breather should only be used for a single patient at a time - do not split the breathing circuit to more than one patient.

- Always have immediate access to an alternative means of ventilation, which is ready for use, in order to reduce the possibility of patient death or serious deterioration of health.

- The Texas Breather ${ }^{\mathrm{TM}}$ should only be used at the direction of a physician with specific training in the use of endotracheal intubation, chemical paralysis, sedation, mechanical ventilation, and bag-valve mask assemblies.

- The Texas Breather ${ }^{\mathrm{TM}}$ should only be used with patients supplied with appropriate paralysis and/or sedation to avoid asynchronous breathing, bucking, and coughing.

- The BVM used with the Texas Breather ${ }^{\mathrm{TM}}$ should include a commercially available pressure relief valve to prevent barotrauma.

- The BVM used with the Texas Breather ${ }^{T M}$ should include a viral filter to trap aerosols containing viral particles in expired air. Personal protective equipment

LBL-1002 rev02

FIGURE 10: Appendix A.2 Instructions for use 


\section{Cureus}

(PPE) is still required.

- The Texas Breather ${ }^{\mathrm{TM}}$ does not include patient monitoring.

- The Texas Breather ${ }^{\mathrm{TM}}$ does not have alarms for device malfunction. Use commercially available accessories for monitoring and audible/visual powerfailure alarms, and for capnographic monitoring pressure and providing audible/visual alarms for low pressure.

- When using supplemental oxygen, do not allow smoking or use unit near sparking equipment, open flame, oil, or other flammable chemicals.

- If PEEP is desired, use a commercially available PEEP valve accessory with the BVM.

- The BVM used with the Texas Breather ${ }^{\mathrm{TM}}$ should include a pressure relief valve suitable for the patient under ventilatory support.

- When using supplemental oxygen, the flow rate from its source should be monitored

- Humidification using a Heat and Moisture Exchanger (HME) on the connected BVM output or Heated Humidification of the input oxygen is recommended for long-term ventilation using this device.

- Settings and use of the device should be adjusted relative to physiologic monitoring such as, but not limited to: End-tidal $\mathrm{CO}_{2}$ monitors, pulse-oximetry, and blood-gas parameters.

- Inspect the device every 4 hours and discontinue use if cracks or other damage to the casing are identified.

- Discontinue use if the motor makes loud or grinding noises.

- Use of this device should follow installation instructions below performed by a qualified biomedical engineer or technician.

- Caution - do not allow fingers, loose clothing, or long hair to come in contact with the cam and rod assembly while the Texas Breather is on. This poses a potential entrapment hazard.

\section{For Biomedical Department}

Installation Instructions (to be performed by qualified biomedical engineer or technician)

1. Perform leakage current test and other tests per local protocol.

This device has not undergone IEC 60601-1 Testing. It uses an IEC 60601-1 certified external power supply (12Vdc, 2A, 2 MOOP).

2. Review placement of device in accordance with AAMI Technical Information Report (TIR) 18, Guidance on electromagnetic compatibility of medical devices for clinical/biomedical engineers Part 1: Radiated radio-frequency electromagnetic energy. This device has not undergone IEC 60601-1-2 testing.

FIGURE 11: Appendix A.3 Instructions for use 


\section{Cureus}

Operating Instructions

\section{Patient preparation-}

1. BVM setup: Prepare the bag-valve mask and accessories for the patient according to manufacturer's instructions for use in invasive ventilation.

- Intubate patient and ventilate the patient by manually operating the BVM until the Texas Breather ${ }^{\mathrm{TM}}$ is setup and ready.

- IMPORTANT: If the patient's chest does not rise and fall with each breath or no airflow is present, the patient's airway or endotracheal tube may be blocked or malpositioned. Take immediate action to clear airway or confirm tube placement. The airway must be clear before proceeding.

2. Add PEEP, pressure relief valves, and viral filter, as required/available into in the BVM breathing circuit. Use of bacteria/viral filter in-line with BVM-endotracheal tube connection is recommended to limit aerosolization of exhaled viral particles. Set up desired patient monitoring and alarms (end-tidal $\mathrm{CO}_{2}$ monitor, pulse-oximetry, respiratory rate detection). CAUTION - the Texas Breather ${ }^{\mathrm{TM}}$ does not have patient monitoring and does not have alarms.

3. Setup and adjust the location of the Texas Breather ${ }^{\mathrm{TM}}$ by mounting the device on a bed mounted IV pole. Position the device so that the BVM can be inserted into the Texas Breather ${ }^{\mathrm{TM}}$ housing minimizing the use of supplemental ventilator tubing (to minimize rebreathing of exhaled air).

FIGURE 12: Appendix A.4 Instructions for use 


\section{Cureus}

\section{Device setup-}

1. Connect the 'Piston Rod' to the motor 'Cam' using the hole pairing for expected tidal volume to be delivered. Table 1 can be used for reference but has not been calibrated for each BVM device.

Table 1 - Initial Controls and Respirator Parameter Recommendations

\begin{tabular}{|c|c|c|}
\hline $\begin{array}{c}\text { Patient } \\
\text { Weight }\end{array}$ & $\begin{array}{c}\text { Rod } \\
\text { Position }\end{array}$ & $\begin{array}{c}\text { Cam } \\
\text { Position }\end{array}$ \\
\hline $50 \mathrm{~kg}$ & $\mathrm{~A}$ & 3 \\
\hline $60 \mathrm{~kg}$ & $\mathrm{~A}$ & 4 \\
\hline $75 \mathrm{~kg}$ & $\mathrm{~A}$ & $\mathbf{5}$ \\
\hline
\end{tabular}

\begin{tabular}{|c|c|c|}
\hline $\begin{array}{c}\text { Patient } \\
\text { Weight }\end{array}$ & $\begin{array}{c}\text { Rod } \\
\text { Position }\end{array}$ & $\begin{array}{c}\text { Cam } \\
\text { Position }\end{array}$ \\
\hline $60 \mathrm{~kg}$ & B & 2 \\
\hline $75 \mathrm{~kg}$ & B & 3 \\
\hline $80 \mathrm{~kg}$ & B & 4 \\
\hline $90 \mathrm{~kg}$ & B & 5 \\
\hline $100 \mathrm{~kg}$ & B & 6 \\
\hline
\end{tabular}

Table 2 - Typical performance measured using benchtop lung simulator with motor controller knob at full $\mathrm{CW}$ position

\begin{tabular}{|c|c|c|c|c|c|c|c|c|c|}
\hline \multirow[b]{2}{*}{$\begin{array}{l}\text { Pin Setting } \\
\text { Piston - Arm }\end{array}$} & \multicolumn{3}{|c|}{$\begin{array}{c}\text { Resistance } 5(\mathrm{cmH} 2 \mathrm{O} / \mathrm{L} / \mathrm{s}) \\
\text { Compliance } 50(\mathrm{~mL} / \mathrm{cmH} 2 \mathrm{O})\end{array}$} & \multicolumn{3}{|c|}{$\begin{array}{c}\text { Resistance } 6(\mathrm{cmH} 2 \mathrm{O} / \mathrm{L} / \mathrm{s}) \\
\text { Compliance } 20(\mathrm{~mL} / \mathrm{mH} 2 \mathrm{O})\end{array}$} & \multicolumn{3}{|c|}{$\begin{array}{l}\text { Resistance } 10(\mathrm{cmH} 2 \mathrm{O} / \mathrm{L} / \mathrm{s}) \\
\text { Compliance } 10(\mathrm{~mL} / \mathrm{cmH} 2 \mathrm{O})\end{array}$} \\
\hline & $\begin{array}{l}\begin{array}{l}\text { Prosssure } \\
\text { (cmH20) }\end{array} \\
\text { (cmH2 }\end{array}$ & $\begin{array}{c}\begin{array}{c}\text { Volume } \\
(\mathrm{mL})\end{array} \\
\end{array}$ & $\begin{array}{c}\text { Respiratory } \\
\text { Rate }\end{array}$ & $\begin{array}{l}\begin{array}{l}\text { Presssuro } \\
\text { (cmH20) }\end{array} \\
\text { (cmH20) }\end{array}$ & $\begin{array}{c}\begin{array}{c}\text { Volume } \\
(\mathrm{mL})\end{array} \\
\end{array}$ & $\begin{array}{c}\text { Rospiratory } \\
\text { Rate }\end{array}$ & $\begin{array}{l}\begin{array}{l}\text { Prosssuro } \\
\text { (cmH20) }\end{array} \\
\text { (cmH20) }\end{array}$ & $\begin{array}{c}\text { Volume } \\
(\mathrm{mL})\end{array}$ & $\begin{array}{c}\text { Rospiratory } \\
\text { Rato }\end{array}$ \\
\hline A-1 & 3.6 & 155 & 29 & 7.2 & 140 & 29 & 12.2 & 110 & 29 \\
\hline B.1 & 5.1 & 220 & 29 & 8.7 & 170 & 29 & 14.5 & 145 & 29 \\
\hline A-2 & 5.3 & 220 & 29 & 10.5 & 200 & 29 & 17 & 160 & 28 \\
\hline A. 3 & 7.2 & 300 & 29 & 14 & 270 & 28 & 22.5 & 220 & 28 \\
\hline B. 2 & 7.6 & 335 & 28 & 14 & 270 & 28 & 23 & 230 & 28 \\
\hline$A-4$ & 9 & 375 & 28 & 17.4 & 320 & 28 & 28 & 275 & 27 \\
\hline B-3 & 10 & 420 & 27 & 18 & 350 & 28 & 32 & 305 & 27 \\
\hline A. 5 & 10.7 & 450 & 27 & 20.5 & 370 & 27 & 34.5 & 325 & 26 \\
\hline B.4 & 12.1 & 530 & 27 & 22 & 420 & 27 & 38.5 & 370 & 26 \\
\hline B. 5 & 14 & 610 & 26 & 26 & 510 & 25 & $\mathrm{~N} / \mathrm{A}$ & N/A & $\mathrm{N} / \mathrm{A}$ \\
\hline B.6 & 15.6 & 700 & 24 & $\mathrm{~N} / \mathrm{A}$ & N/A & N/A & N/A & $\mathrm{N} / \mathrm{A}$ & $\mathrm{N} / \mathrm{A}$ \\
\hline
\end{tabular}

LBL-1002 rev02 


\section{Cureus}

2. Turn on the Texas Breather ${ }^{\mathrm{Tm}}$ and observe that the device piston assembly is operational.

3. Plug the Texas Breather into a power failure alarm (PFA) and plug the PFA into a grounded wall receptacle that has power backup or an uninterruptable power supply.

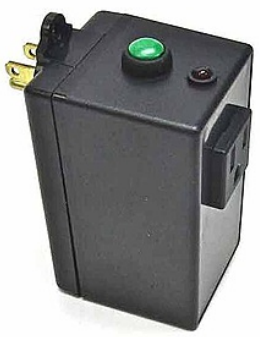

Power failure alarm functionality:

oss of power: Audible alarm, red LED flashes

Plug disconnection: Audible alarm, red LED flashes

Alarm silencing:

User presses green button

Red LED flashes until fault condition removed

4. Select the respiratory rate by turning motor controller knob:

- clockwise to increase ventilatory rate

- counterclockwise to decrease ventilatory rate

Controller settings between $50 \%$ and $100 \%$ are recommended for optimal

motor performance. Lower power settings may cause motor to stall when forcefully delivering respirations.

5. Turn off Texas Breather ${ }^{T M}$ while the piston is in furthest out position.

6. Place the assembled BVM into the Texas Breather ${ }^{\mathrm{TM}}$ housing

7. Turn on the Texas Breather ${ }^{\mathrm{TM}}$ device and observe powered activation of the BVM.

During Use

Monitor the patient and adjust respiratory rate and degree of compression as clinically indicated.

- If adjustments in tidal volume are required:

1. [Texas Breather ${ }^{\text {Tm }}$ ] - Use motor controller to stop motor while the piston is in furthest out position.

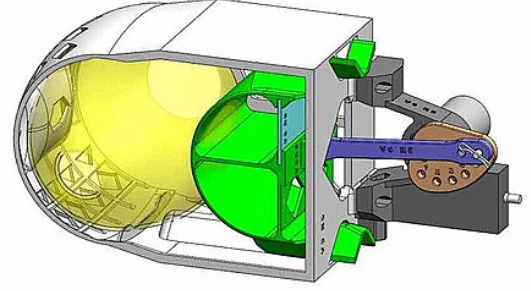

LBL-1002 rev02

FIGURE 14: Appendix A.6 Instructions for use 


\section{Cureus}

2. $[B V M]$ - Disconnect BVM from endotracheal tube.

3. Remove BVM from Texas Breather" housing (Fig. 1D) and use the BVM to manually ventilate the patient while making adjustments. 4. [Texas Breather ${ }^{\mathrm{Tm}}$ ] - Remove piston rod connection pin and move pin and piston rod to another hole on the adjustable cam. Tables 1 and 2 can be used for reference but has not been calibrated for each BVM device.

- Piston Rod: Hole A provides lower tidal volume than hole B (Fig. 1B)

- Cam: Higher numbered holes provide larger tidal volumes (Fig. 1C)

5. [Texas Breather ${ }^{\text {rt }}$ ] - Secure pivot arm pin between Rod and Cam

6. Place BVM back into Texas Breather ${ }^{\text {Tu }}$ housing and reconnect to endotracheal tube

7. [Texas Breather ${ }^{\mathrm{Tm}}$ ] - Restart motor by using controller

- If adjustments in respiratory rate are required:

1. Use motor controller to adjust speed of motor rotation

- clockwise to increase ventilatory rate

- counterclockwise to decrease ventilatory rate

Controller setting between $50 \%$ and $100 \%$ is recommended for optimal motor performance.

- Inspect the device every 4 hours, discontinue use if the motor makes loud or grinding noises, or if cracks or other damage to the casing are identified.

Caution - do not allow fingers, loose clothing, or long hair to come in contact with the cam and rod assembly while the Texas Breather is on. This poses a potential entrapment hazard.

\section{Cleaning}

Limited testing with $70 \%$ isopropyl alcohol has been performed. Cleaning

should be performed in accordance with hospital protocols.

DO NOT submerge the device in any liquid!

The device is not intended for reprocessing.

FIGURE 15: Appendix A.7 Instructions for use

\section{Additional Information}

\section{Disclosures}

Human subjects: All authors have confirmed that this study did not involve human participants or tissue. Animal subjects: All authors have confirmed that this study did not involve animal subjects or tissue. Conflicts of interest: In compliance with the ICMJE uniform disclosure form, all authors declare the following: Payment/services info: All authors have declared that no financial support was received from any organization for the submitted work. Financial relationships: Chris Danek declare(s) Licensing agreement from Bessel LLC. We declare that one author, Chris Danek, director of Bessel LLC, has licensed the rights from Texas Tech University Health Sciences Center El Paso to distribute the innovation. The other authors declare that there are no conflicts of interest. No additional funding was provided for this project. . Intellectual property info: The members of the Texas Tech Office of Research Commercialization (Cameron Smith, Hutton Jones) are working directly with the Office of Technology Commercialization (Chao Zhang) and the Assistant Vice President (Ivette Savina) at UTEP. Both entities are supportive of our efforts, and are committed to avoiding any intellectual property impediments. Both TTU and UTEP are aware of the urgency of this project, and there is tentative agreement that the device will be offered with a 1 year low cost option, and thereafter a royalty agreement will be established. There also is agreement that the Universities will file patents and other intellectual property protections jointly. We are aware of a utility patent (US 6155257) on a similar concept. This patent expired on 10/7/2018. Our preliminary patent search has not revealed any other conflicting prior art. . Other relationships: All authors have declared that there are no 
other relationships or activities that could appear to have influenced the submitted work.

\section{Acknowledgements}

The authors would like to thank the Training and Educational Center for Healthcare Simulation (TECHS) at Texas Tech University Health Sciences Center (TTUHSC) El Paso for providing testing equipment. Additional design and manufacturing support was provided by the UTEP W.M. Keck Center for 3D Innovation. A specific acknowledgement to each of the staff for their contributions including Mireya Flores, Frank Medina, David Espalin, Nikki Martinez, Jose Coronel, Angel Vega, Leonardo Gutierrez, and Mahesh Tonde. Material donation and additional manufacturing assistance was also supported through the generous contribution of Stratasys Co. Ansys Inc. supported simulation modeling. The authors would also like to acknowledge the support and insight from Joel Libove (Furaxa) on the electrical design of the device; and Cindy Domecus for guidance in the U.S. FDA submission and review process.

\section{References}

1. Xu Z, Shi L, Wang Y, et al.: Pathological findings of COVID-19 associated with acute respiratory distress syndrome. . Lancet Respir Med. 2020, 8:420-422. 10.1016/S2213-2600

2. Gattinoni L, Chiumello D, Caironi P, Busana M, Romitti F, Brazzi L, Camporota L: COVID-19 pneumonia: different respiratory treatments for different phenotypes?. Intensive Care Med. 2020, 46:1099-1102. 10.1007/s00134-020-06033-2

3. Ventilator management strategies for adults with acute respiratory distress syndrome . (2020). Accessed: March 15 2020: https://www.uptodate.com/contents/ventilator-management-strategies-for-adults-withacute-respiratory-distress-syndrome.

4. Acute Respiratory Distress Syndrome Network, Brower RG, Matthay MA, Morris A, Schoenfeld D, Thompson BT, Wheeler A: Ventilation with lower tidal volumes as compared with traditional tidal volumes for acute lung injury and the acute respiratory distress syndrome. N Engl J Med. 2000, 342:1301-1308. 10.1056/NEJM200005043421801

5. Truog RD, Mitchell C, Daley GQ: The toughest triage-allocating ventilators in a pandemic . N Engl J Med. 2020, 382:1973-1975. 10.1056/NEJMp2005689

6. Ranney ML, Griffeth V, Jha AK: Critical supply shortages-the need for ventilators and personal protective equipment during the Covid-19 pandemic. N Engl J Med. 2020, 382:41. 10.1056/NEJMp2006141

7. Ajao A, Nystrom SV, Koonin LM, et al.: Assessing the capacity of the US health care system to use additional mechanical ventilators during a large-scale public health emergency. Disaster Med Public Health Prep. 2015, 9:634-641. 10.1017/dmp.2015.105

8. Khoury A, Sall FS, De Luca A, Pugin A, Pili-Floury S, Pazart L, Capellier G: Evaluation of bag-valve-mask ventilation in manikin studies: what are the current limitations?. Biomed Res Int. 2016, 2016:4521767. $10.1155 / 2016 / 4521767$

9. Openlung emergency medical ventilator. (2020). Accessed: May 11 2020: https://gitlab.com/open-sourceventilator/ventilator/OpenLung.

10. MPS open-source ventilator. (2020). Accessed: April 6 2020: https://www.monolithicpower.com/en/mpsopen-source-ventilator.

11. MIT emergency ventilator (e-vent) project. (2020). Accessed: May 11 2020: https://emergencyvent.mit.edu/.

12. Bein T, Grasso S, Moerer O, et al.: The standard of care of patients with ARDS: ventilatory settings and rescue therapies for refractory hypoxemia. Intensive Care Med. 2016, 42:699-711. 10.1007/s00134-0164325-4

13. Hess DR: Respiratory mechanics in mechanically ventilated patients . Respir Care. 2014, 59:1773-1794. 10.4187/respcare.03410

14. Food and drug administration, FDA combating covid-19 with medical devices . (2020). Accessed: March 26 2020: https://www.fda.gov/media/136702/download.

15. ISO, ISO 80601-2-80: 2018, in medical electrical equipment - part 2-80: particular requirements for basic safety and essential performance of ventilatory support equipment for ventilatory insufficiency. (2018). Accessed: April 15 2020: https://www.iso.org/standard/68844.html.

16. Association for the advancement of medical instrumentaiton (AAMI), emergency use resuscitator system (EURS) design guidance. (2020). Accessed: April 15 2020: https://www.aami.org/docs/defaultsource/standardslibrary/200410_cr503-2020_rev1.pdf.

17. The bag II disposable resuscitator . (2020). Accessed: April 22 2020: https://www.laerdal.com/us/products/medical-devices/airway-management/the-bag-ii-disposableresuscitator/..

18. CareFusion AirLife ${ }^{\circledR}$ manual self-inflating resuscitation devices . (2013). Accessed: April 222020 : https://www.vyaire.com/products/self-inflating-resuscitation.

19. Rusch manual resuscitator bag. (2020). Accessed: April 22 2020: https://www.quadmed.com/product/ruschdisposable-manual-resuscitator.

20. $\quad \mathrm{Ambu}^{\circledR}$ SPUR ${ }^{\circledR} \mathrm{II}$ - disposable resuscitator . (2020). Accessed: April 22 2020:

https://www.ambuusa.com/emergency-care-and-training/resuscitators/product/ambu-spur-ii.

21. Ferno single patient use bvm with medication and monitoring port . (2020). Accessed: April 22 2020: https://fernoems.com/oxygen-airway/single-patient-use-bvm.

22. Laerdal silicone resuscitators. (2017). Accessed: April 22 2020: https://laerdal.com/gb/doc/117/LaerdalSilicone-Resuscitators-LSR.

23. U.S. Food and drug administration emergency use authorization for ventilators during covid-19 pandemic . (2020). Accessed: March 24 2020: https://www.fda.gov/media/136423/download. 